\title{
Experiências pioneiras de participação popular no urbano: novos desafios ao assistente social
}

\author{
Pioneering experiences of popular participation in the urban: \\ new challenges to the social worker
}

\section{Natália Coelho de Oliveira*}

\begin{abstract}
Resumo - Este artigo reflete parte da contribuição e produção acadêmica de assistentes sociais acerca das experiências de trabalho com educação e participação popular realizadas entre as décadas de 1960 e 1980, com base na pesquisa documental em artigos da Revista Serviço Social e Sociedade e nas principais obras datadas deste período histórico. Esse período possibilitou um avanço no trabalho de conscientização e educação popular junto aos movimentos populares urbanos, proporcionando um legado teórico-metodológico para a categoria profissional e relevantes reflexões sobre a nossa prática. Além disso, também cabe ao artigo levantar alguns desafios de caráter comparativo ao tempo presente no que tange ao trabalho social desenvolvido no Programa Minha Casa Minha Vida (PMCMV), principal programa habitacional brasileiro.

Palavras-chave: participação popular; educação popular; Serviço Social; urbano; habitação.
\end{abstract}

\begin{abstract}
This article reflects part of the contribution and academic production of social workers on work experiences with education and popular participation carried out between the 1960s and 1980s, based on documentary research in articles of the Brazilian journal Revista Serviço Social e Sociedade and in the main works dating from that historical period. This period allowed an advance in the raising of awareness and popular education with the popular urban movements, providing a theoretical and methodological legacy for the professional category and relevant reflections on our practice. In addition, it is also up to the article to raise some comparative challenges to the present time regarding the social work developed in the government program Minha Casa, Minha Vida (PMCMV), the main Brazilian housing program.
\end{abstract}

Keywords: popular participation; popular education; social work; urban; housing.

\footnotetext{
* Assistente Social. Especialista em Política e Planejamento Urbano (IPPUR-UFRJ) e em Dinâmicas Urbano-Ambientais e Gestão do Território (UERJ). Mestre em Serviço Social. Professora Substituta em Serviço Social (UFF Rio das Ostras). Correspondência: Universidade Federal Fluminense - Pólo Universitário de Rio das Ostras (PURO): Rua Recife, s/n, Jardim Bela Vista, Rio das Ostras - RJ. CEP: 28895-532. Email:<nataliacoelho2014@gmail.com>.
} 


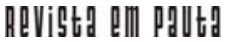

\} EXPERIÊNCIAS PIONEIRAS DE PARTICIPAÇÃO POPULAR - OLIVEIRA, N. C. \}

DOI: $10.12957 /$ REP.2017.32740

A estrutura do artigo propõe apresentar a produção intelectual da categoria profissional no período de maior visibilidade no trabalho com educação popular e mobilização comunitária, a partir dos anos 1960. Além disso, apresenta o trabalho em assessoria aos movimentos sociais urbanos, na década de 1980, que demonstra um período rico de aproximação entre o profissional e a população, a partir da mobilização, conscientização e participação popular.

Por meio da crítica ao desenvolvimento de comunidade, durante as décadas de 1950 e 1960, o Serviço Social, em sua prática, desenvolveu junto ao trabalho com comunidade a participação social vinculada à promoção do desenvolvimento econômico de forma acelerada, com vistas à superação do "atraso" urbano e social. Influenciada pelo questionamento desta prática e pelo contexto histórico, a categoria profissional busca novas bases de legitimação e elabora um método de trabalho social de perspectiva mais crítica, considerando as particularidades da realidade social.

Com esta vinculação clara e o compromisso da classe trabalhadora com o processo de reconceituação do Serviço Social, foi desenvolvido um vínculo orgânico com a população na prática profissional. Este período foi marcado pelo movimento de ruptura com a burocracia e tecnificação no trabalho do assistente social. Ademais, o reconhecimento da dimensão política do exercício profissional possibilitou um trabalho mais amplo de conscientização e mobilização social com movimentos urbanos de luta pelo direito à cidade.

Neste sentido, vamos verificar tais mudanças de conceito da prática profissional no que tange ao trabalho social nos programas de habitação popular, especialmente o Programa Minha Casa Minha Vida (PMCMV), o maior programa habitacional com disponibilidade de recursos financeiros e de maior abrangência no que se refere à produção habitacional no país. Por meio dos documentos institucionais do Ministério das Cidades e da Caixa Econômica Federal, órgãos formuladores e fiscalizadores que constroem regras e parâmetros de ação para o trabalho social, verificaremos novos significados que imprimem um conteúdo à prática profissional do assistente social no campo da habitação.

\section{Desenvolvimento}

\subsection{Mobilização comunitária e Serviço Social}

O tema mobilização comunitária começou a ser discutido nos Seminários de Desenvolvimento de Comunidade durante o período entre 1951 e 1966. Nestes seminários, a temática desenvolvimento de comunidade, entendida geralmente como instrumento de trabalho, era compreendida como uma: 
técnica que, tendo por base, a discussão de assunto específico, em grupos informais de debate, levam seus integrantes, elementos representativos da comunidade (lideranças, entidade e povo) intencionalmente organizados, a uma tomada de consciência dos problemas e recursos da mesma, tornando-os preparados a realizarem trabalho onde prevaleça o espírito comunitário em uma forma coordenada e harmônica. (AMMANN, 2013, p. 214).

Expressava uma construção ideológica tipicamente funcionalista, com foco sobre o controle do processo de intervenção, esmiuçado em procedimentos, etapas e instrumentos. No livro Manual de operacionalização de Serviço Social de comunidades, citado por Ammann (2013), esboçamse didaticamente as etapas do processo como técnicas a serem desenvolvidas pelos assistentes sociais, tais como: o diagnóstico, a programação e a intervenção social. Como exemplifica a referida autora, "O assistente social preocupa-se em conhecer a cultura da comunidade, principalmente suas normas e valores. É preciso que o técnico ajude as pessoas a compreenderem os porquês de determinadas situações ou bloqueios" (AMMANN, 2013, p. 216). Dessa forma, este era o objetivo para construir o diagnóstico e basear sua intervenção profissional.

A partir de uma perspectiva dialética que leva em conta o contexto histórico das relações sociais e os processos de dominação e exploração vigentes nas sociedades capitalistas, são elaborados outros conceitos de participação social, os quais consideram a participação social no cotidiano como prática social concreta. Influenciados por Lefebvre, por exemplo, as formas de participação analisadas por Lima (1979) concebem o cotidiano como centro real da práxis, em que o processo produtivo desempenha um papel fundamental.

A articulação entre os movimentos sociais e o desenvolvimento de comunidade foi gestada com as experiências de movimentos de educação de base, junto aos sindicatos rurais, procurando estabelecer um vínculo orgânico entre intelectuais e as classes dominadas, pelo viés dos movimentos sociais. Outras obras foram elaboradas, como Serviço Social de comunidade numa visão de práxis, produzido por Silva (1983) com o objetivo de construir uma base para a práxis social, a partir de um suporte metodológico, analisando o processo de ensino-aprendizagem do Serviço Social de comunidade nos currículos dos cursos das Escolas de Serviço Social, estreitando o trabalho da universidade junto aos bairros populares.

Nesses estudos, foi verificada a influência do Serviço Social de comunidade na formação de técnicos e "alguns reivindicam que a ação deveria contribuir para o avanço da consciência política do povo brasileiro através de trabalhos junto à população explorada e oprimida, partindo da luta de classes" (AMMANN, 2013, p. 220)

Os que acreditam na práxis transformadora, a partir da adoção de uma perspectiva dialética, passam a ter um posicionamento que privilegia 


\section{ReVistg QIII PaUtg}

\} EXPERIÊNCIAS PIONEIRAS DE PARTICIPAÇÃO POPULAR - OLIVEIRA, N. C. \}

DOI: $10.12957 /$ REP.2017.32740

os movimentos populares "como alternativa de práticas extrainstitucionais, dentre elas os sindicatos, as comunidades eclesiais de base, as associações de moradores, etc." (AMMANN, 2013, p. 220). Alguns até consideravam que o Serviço Social deveria optar somente pelas organizações populares, pois é a partir delas que se conhece a realidade concreta da população. Acreditavam, ainda, que apenas desse modo poderiam "liberar o Serviço Social da dependência institucional, ou seja, do Estado e da classe dominante" (AMMANN, 2013, p. 220). Tal perspectiva integrava um dos temas característicos dos debates profissionais, na transição aos anos 1980, sobre os limites e possibilidades do trabalho do assistente social nas instituições. Assim, Silva (apud AMMANN, 2013, p. 220) defendia que os movimentos sociais são alternativas que propiciam "maior liberdade de ação, oferecendo uma prática profissional mais comprometida com as classes populares".

Cabe destacar a importância do conceito de práxis social, à época, para pensar a ação profissional, na qual a ação transformadora de uma realidade propunha a construção de um novo projeto de sociedade a partir da prática social consciente. Tendo como base o movimento de ação-reflexão, tal projeto de ação visava à participação no cotidiano e ao seu engajamento nos movimentos populares, ainda com a preocupação dos interesses da população usuária.

A autora Maria Luiza de Souza, na sua obra Desenvolvimento de comunidade e participação, propõe o processo pedagógico de "autonomização das camadas populares e enfrentamento dos interesses e preocupações da população comunitária", introduzindo no conceito de comunidade uma perspectiva de classes sociais (AMMANN, 2013, p. 222)

Ammann (2013) salienta que o ponto de vista de Souza baseia-se na centralidade do local de moradia enquanto ponto de encontro entre o desenvolvimento de comunidade e os movimentos populares, assim como os espaços de moradia podem possibilitar uma transformação social. Então é estimulada e desenvolvida a participação, considerada como "processo que se expressa através da conscientização, organização e capacitação contínua e crescente da população ante a sua realidade concreta" (AMMANN, 2013, p. 223).

\subsection{O Serviço Social e a inserção nos movimentos sociais}

A reorganização da sociedade civil no processo de redemocratização do país, em meados da década de 1980, recoloca ao Serviço Social o debate sobre o compromisso com a classe trabalhadora, "principal protagonista das lutas sociais no período" (AMMANN, 2013, p. 232). Por um lado, a crítica sobre o desenvolvimento de comunidade "desvendara seu caráter ideológico, reiterativo e manipulador". Por outro, o processo de reconceituação do Serviço Social "apontara os limites da ação profissional no interior das instituições" (AMMANN, 2013, p. 230). Considerava-se que 


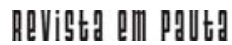

\} EXPERIÊNCIAS PIONEIRAS DE PARTICIPAÇÃO POPULAR - OLIVEIRA, N. C.

DOI: $10.12957 /$ REP.2017.32740

o papel legitimador das instituições, no que concerne à dominação e à exploração de classe, "exerce um consentimento das classes dominadas para assegurar a hegemonia dominante sobre o conjunto da sociedade" (AMMANN, 2013, p. 230).

Inicia-se, neste momento, uma crítica à participação social, que era pautada nos projetos de desenvolvimento de comunidade nas décadas de 1950 e 1960, quando a ação comunitária tinha o papel de "acelerar o desenvolvimento, nos moldes em que ele é ditado pelo poder central", ou seja, pelo Governo Federal. Como relata Ammann (1980) em artigo para a Revista Serviço Social e Sociedade, tecendo a discussão das críticas sobre o conceito de participação:

As populações envolvidas nesses programas compete legitimar as aludidas diretrizes, oferecer apoio logístico e mão-de-obra - quase sempre gratuita - para a execução e eficácia das mesmas. O desenvolvimento local transforma-se numa variável dependente dos modelos de desenvolvimento nacional, não se questionando a validade e justeza dos mesmos. O desenvolvimento é então identificado com as plataformas de governo, cabendo ao Estado promovê-lo, planificá-lo e ditar o que é bom e o que não é bom para os brasileiros. (AMMANN, 1980, p. 153).

O debate no interior da categoria nessa época era um dilema do assistente social por atuar como funcionário das instituições e, assim, colaborar com a classe dominante na exploração da classe trabalhadora. Nesse sentido, a profissão experimentou outros campos extrainstitucionais e iniciou a produção de um novo projeto profissional, distante dos modelos que reforçavam a ideologia dominante.

A ação com os movimentos populares se deu como uma alternativa de criação de um vínculo orgânico com a classe dominada, como foi o caso do Chile, no início de 1970. No Brasil, somente no final da década de 1970 as universidades passaram "a definir seu campo de prática com base em grupos engajados em lutas de transformação social", com maior visibilidade (AMMANN, 2013, p. 230).

Como exemplos dessas experiências, podemos ressaltar a participação dos cursos de Serviço Social da PUC-SP e da Universidade de Brasília (UNB), os quais socializaram suas publicações, principalmente na Revista Serviço Social e Sociedade, na qual podemos encontrar esses registros. Ali, é possível verificar que essas práticas eram desenvolvidas nas disciplinas de Serviço Social de comunidade com muitos alunos que estavam praticando o estágio. Um dos exemplos da experiência de Brasília foi com o movimento popular da comunidade de Ceilândia, com associações de bairros, conhecido como os "Incansáveis".

Ammann (2013) relata que, dentre as ações desenvolvidas, estavam o auxílio na oferta de informações sobre legislação, políticas sociais e trâmites legais de processo judicial; na confecção e reprodução de suas histórias; na 


\section{ReVistg QIII PaUtg}

\} EXPERIÊNCIAS PIONEIRAS DE PARTICIPAÇÃO POPULAR - OLIVEIRA, N. C. \}

DOI: $10.12957 /$ REP.2017.32740

elaboração de documentos para envio de autoridades; em manifestos, cartas e abaixo-assinados; em suporte na organização de assembleias, reuniões e plenárias; na realização de visitas domiciliares e convocações para encontros; na explicação da situação legal dos lotes etc.

A prática do Serviço Social da PUC de São Paulo junto ao movimento popular se deu por meio da criação de um projeto-piloto com a população residente na periferia da cidade. Foi concretizada pela inserção do Movimento de Loteamentos Clandestinos, cujos objetivos, em 1978, eram conscientizar os moradores dos loteamentos quanto à situação da ocupação, aumentar a participação dos moradores nos bairros, formar lideranças, organizar permanentemente o bairro e articular este movimento a outros da cidade (AMMANN, 2013).

A atuação dos assistentes sociais consistia no assessoramento à população no contato com as instituições e órgãos responsáveis para resolução dos problemas dos bairros. Desse modo, organizavam ida coletiva à prefeitura, socializavam informação e mapeavam a área. Os assistentes sociais procuravam institucionalizar a demanda e as reivindicações dos moradores por meio das ações da prefeitura, prioridades estas que foram, muitas vezes, redimensionadas com a pressão popular.

Sendo assim, o assessoramento à população, de modo a preparar o trabalho de pressão junto à prefeitura, cooperou no sentido de levantar as reais necessidades da área no que se refere à infraestrutura e aos equipamentos sociais. Eles problematizavam com a população a precariedade ou inexistência dos serviços urbanos, questionando os interesses assumidos pela gestão pública, o papel e o significado dos movimentos populares na concretização das reivindicações, elaboração de estratégias coletivas, fortalecimento da organização popular e articulação com outros movimentos de nível regional. Nesse sentido, seu saber técnico encontrava-se socializado junto à população.

O artigo intitulado O Serviço Social e os movimentos sociais uma experiência de trabalho em loteamentos clandestinos, da Revista Serviço Social e Sociedade, de 1981, é fruto da vivência de alunos de estágio, de modo que eles puderam produzir seus trabalhos de conclusão de curso sobre essa experiência. Isso nos mostra que a intenção dessas experiências foi de superar uma visão fragmentada da realidade.

A perspectiva da atuação profissional nesses projetos-piloto parte de algumas premissas, tais quais: a) as mudanças são fruto de confrontos de interesses antagônicos; b) as lutas urbanas são contradições do modo de produção capitalista; c) a luta pela legalização da terra faz parte da melhoria das condições de vida dos trabalhadores urbanos; e d) a população é sujeito da transformação social e a saída se dará por meio da sua organização e mobilização social. Tais pressupostos demonstram um movimento de ruptura com uma prática profissional, marcada pela burocracia e tecnificação. Essa 


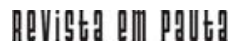

\} EXPERIÊNCIAS PIONEIRAS DE PARTICIPAÇÃO POPULAR - OLIVEIRA, N. C. \}

DOI: $10.12957 /$ REP.2017.32740

ação é sempre voltada para o fortalecimento de políticas sociais no entorno de um Estado fortemente autoritário e centralizador.

O reconhecimento da sua dimensão política, na contribuição do processo de conscientização e mobilização social, é visto como um confronto de posições que possibilita saltos qualificativos na organização da população. É nesse contexto que o Serviço Social passa a adotar o método das Ciências Humanas, a Investigação-Ação, como uma primeira aproximação com a realidade, por meio de participação de atividades significativas com a comunidade para o entendimento da população, sua forma de organização e suas expressões. Assim, considera-se que a sistematização e elaboração científica complementam a sua ação, entendendo o assistente social enquanto agente da transformação.

No artigo da Revista Serviço Social e Sociedade intitulado Profissional-População uma luta conjunta, elaborado por Araújo et al. (1982, p. 36), é retratado o trabalho de mobilização, orientação e encaminhamento realizado por assistentes sociais em favelas da Zona Norte de São Paulo, próximas ao Rio Tietê, no ano de 1976. A partir da fala dos moradores é perceptível que os assistentes sociais contribuíam para a organização interna dos mesmos, colaborando com informações, propiciando condições para sua auto-organização na luta por luz, água, creche universitária e urbanização dos loteamentos, e, considerando que a população acreditava que a equipe profissional tinha respaldo institucional, a concretização das meIhorias urbanas pelos órgãos públicos, reivindicadas pelos moradores, era melhorada.

As reflexões de Siqueira et al. (1982) contribuem para essa análise. O artigo da Revista Serviço Social e Sociedade chamado As contradições e o espaço profissional na prática do assistente social demonstra a atuação dos assistentes sociais na assessoria à organização popular com o movimento social urbano das favelas Funerária e Beibinha, em São Paulo, a partir de depoimentos de assistentes sociais que realizaram esse trabalho.

Nesse artigo, uma profissional deixa claro que o objetivo da atuação profissional era 1) fazer com que a população assumisse a posição de agente da história, a partir de sua participação pessoal e na mobilização do conjunto de lutas em busca da solução de suas necessidades; 2) elevar seu nível de consciência à medida que passasse por experiências vivas, vivenciadas através do processo de luta; e 3) contribuir para o seu grau de organização, comunitária e social.

Dessa forma, esse trabalho de fomento à participação social possibilitou construir junto dos moradores uma pauta de reivindicações que se relacionam às necessidades fundamentais da população na periferia, desde o direito à moradia até os serviços de infraestrutura urbana, creches, hospitais, escolas etc. Assim, como contribuir para o reconhecimento da luta dos movimentos sociais urbanos e a formação de compromissos assumidos pelo Poder Público para obtenção das suas reivindicações? Nesse sentido, mecanismos 


\section{ReVistg all pgutg}

\} EXPERIÊNCIAS PIONEIRAS DE PARTICIPAÇÃO POPULAR - OLIVEIRA, N. C. \}

DOI: $10.12957 /$ REP.2017.32740

coletivos de fortalecimento de organização popular foram criados com a atuação da equipe de Serviço Social nas favelas, a fim de que a população pudesse avançar nas suas pautas prioritárias para socialização dos benefícios da urbanização para os moradores, na promoção do direito à cidade.

Lefevbre (2001) salienta que a cidade é produto de interações sociais, a partir de relações de vizinhança, que adquire sentido como forma urbana. Sendo assim, a forma urbana também é apropriada pelos moradores e se ressignifica. A noção de direito à cidade, defendida pelo autor, compreende que os moradores têm necessidades vitais, para além do espaço físico da casa, como por exemplo: sentir, conversar, ver, experimentar, praticar atividades lúdicas e criar símbolos sobre o seu modo de vida. Seguindo esse pensamento, os homens são criadores do seu habitar.

Para Safira Ammann (2013), esse processo de inserção do Serviço Social no movimento popular possibilitou algumas conclusões, tais quais: a atuação dos diversos atores no processo de luta; o desvelamento de que a realidade não ocorre de imediato, mas é uma ação e uma reflexão duradoura, que deve ultrapassar a aparência; a identificação dos grupos que se formam a partir das necessidades concretas; e a definição de que o agente técnico não pode ir aos grupos com programas prontos, visto que os grupos já têm vivências e práticas sociais próprias, a partir das suas necessidades. Ressalta, também, que o grupo caminha com maior riqueza quando está calçado na ação.

Dessa forma, o legado teórico-metodológico construído pela categoria profissional, nas décadas anteriores de acúmulo de experiências junto à população-alvo das intervenções habitacionais e urbanas, sofreu algumas modificações profissionais a partir de novas requisições socioinstitucionais. Essas requisições acabaram por automatizar e burocratizar esta prática profissional com o excesso de normatização que temos hoje no trabalho social desenvolvido no PMCMV, cuja estrutura vem se modificando desde a década de 1990 com o Habitar Brasil BID (HBB). Isso é salientado por Santana (2013) a partir de experiências de trabalho com comunidades em Belém do Pará e com o trabalho social desenvolvido nas favelas do Rio de Janeiro, ambos com recursos do Banco Interamericano de Desenvolvimento (BID), de acordo com Gomes (2006).

Soma-se a esse legado teórico-metodológico profissional e ideopolítico o movimento construído pelo Serviço Social na elaboração do currículo mínimo em Serviço Social (1982), na construção do novo código de ética de 1993, na formulação das Diretrizes Curriculares da Abepss (1996) e na construção do Projeto Ético-Político (PEP). Tais processos representaram para o Serviço Social um novo horizonte profissional ético-político, destacando os principais eixos prioritários que demonstravam esse amadurecimento na relação entre assistente social e usuário: defesa da autonomia, emancipação e plena expansão dos indivíduos sociais, além de imprimir um olhar sobre a realidade e o reconhecimento do significado profissional, 


\section{Revigtg all pgutg}

\} EXPERIÊNCIAS PIONEIRAS DE PARTICIPAÇÃO POPULAR - OLIVEIRA, N. C.

DOI: $10.12957 /$ REP.2017.32740

como retratam lamamoto (2008) e Cardoso (1997). Esta arena de conquistas ideopolíticas profissionais assume um corpo profissional.

\subsection{O Trabalho Social (TS) na atualidade}

Esses avanços, no que tange às conquistas democráticas e à participação social da sociedade civil, foram se alterando nas décadas de 1990. Atualmente, impactam o trabalho social no PMCMV, a partir da forma com que os temas de mobilização popular são apresentados nos textos institucionais. O tema da participação social foi aparecendo de outras maneiras, como associativismo e mobilização comunitária nas atividades do trabalho social (TS). Além disso, foi apresentado de modo a ser estimulado em oficinas abertas em que os técnicos devem abordar, junto às famílias, possibilidades de se unirem e se organizarem em defesa de interesse comum, tanto se associando por grupos de apoio, quanto por comissões para reivindicar melhores condições de vida, saúde, transporte etc. Dessa maneira, as novas requisições socioinstitucionais do trabalho social para o debate da mobilização comunitária foi se transformando e adquirindo outros conceitos nos documentos institucionais do Ministério das Cidades e da Caixa Econômica Federal.

Segundo o Ministério das Cidades, o trabalho técnico social é um dos componentes dos projetos habitacionais do Programa Minha Casa Minha Vida (PMCMV), que compreende um conjunto de estratégias, processos e ações. Os projetos de trabalho social devem estar fundamentados a partir de estudos e diagnósticos integrados e participativos do território, compreendendo as seguintes dimensões: social, econômica, produtiva, ambiental e político-institucional do território e da população beneficiária, além das características de intervenção, visando promover o exercício da participação e a inserção social dessas famílias. Para tanto, torna-se necessária a articulação com as demais políticas públicas, contribuindo para a melhoria da qualidade de vida e para a sustentabilidade dos bens, equipamentos e serviços implantados (BRASIL, 2014b).

Nos documentos institucionais do Ministério das Cidades, em conjunto com a Caixa Econômica Federal, assim como no material dos cursos de capacitação para profissionais de todo o território nacional, por meio do EAD Trabalho Social (BRASIL, 2014a), a ação de mobilização, organização e fortalecimento social "é entendida como uma ação pedagógica e que visa a desenvolver o senso crítico e, como objetivo fim, a maior democratização da sociedade". Paz e Taboada (2010, p. 49) contribuem com essa perspectiva, afirmando que esta ação "incentiva a autonomia, fortalece a autoestima e os laços de solidariedade entre os participantes daquela intervenção e entre os que estão em situação análoga à sua". Esta nova metodologia de trabalho social está sustentada em três pilares: o estímulo da noção de empoderamento; ideia de pertencimento aos moradores e organizações da 


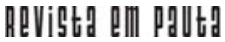

\} EXPERIÊNCIAS PIONEIRAS DE PARTICIPAÇÃO POPULAR - OLIVEIRA, N. C. \}

DOI: $10.12957 /$ REP.2017.32740

sociedade civil e populares; estabelecimento de redes no território. A ideia de empoderamento surge da concepção e do reconhecimento de que os moradores são agentes sociais da mudança. A partir do diálogo entre conjunto de famílias, reuniões de grupos e assembleias, "o trabalho social deve consolidar as informações a serem trazidas e definir mecanismos de discussão para ampliar a participação" (BRASIL, 2014c, p. 53). Como menciona o material do curso de capacitação para técnicos do Ministério da Cidade:

também não se trata de transferir para a sociedade organizada as responsabilidades que são do Estado na formulação ou implantação de políticas públicas, sob o discurso da participação. A comunidade mobilizada precisa conhecer profundamente seus direitos e a quem cabe atendêlos. (BRASIL, 2014c, p. 49).

Observando as portarias ministeriais, deve ser priorizada a organização de grupos e segmentos mais vulneráveis, tais quais de mulheres, idosos, deficientes físicos e jovens, pela identificação de conflitos de gênero, geracionais e de preconceitos. O reconhecimento de tais conflitos acontece ao se perceber que esses grupos enfrentam desafios diferenciados para serem reconhecidos socialmente no espaço urbano, considerando uma visão legítima e que trata dos diferentes com equidade social. Contudo, essa segmentação dos moradores permite uma certa fragmentação na ação coletiva. Tais órgãos indicam uma ação mais focalizada nas oficinas do TTS.

A homogeneização do público ao qual o trabalho social atende é classificado, segundo Pimentel (2012 p. 7), pelas suas condições de vida. Portanto, os eixos do TS de mobilização e organização comunitária pressupõem total desarticulação destes grupos ou apresentam, conforme a autora, um "novo" padrão de associativismo e participação comunitária. As ações de geração de trabalho e renda são construídas a partir das potencialidades dos moradores e comunidade. Além disso, as ações de educação sanitária, ambiental e patrimonial são constituídas a partir da perspectiva para a educação popular, de forma a contribuir para alteração dos modos de vida, construindo novas relações sociais e influências culturais na medida em que os moradores vão se adaptando à "nova condição de moradia" e realidade social, solicitando uma vida mais formal do que antes era experimentada. Esta é a lógica do desenvolvimento comunitário, expresso nas normativas que solicitam um lugar do trabalho social que se remete às antigas funções de controle da classe trabalhadora por meio da moradia, experimentadas no trabalho social com comunidades nas nossas origens profissionais, nas décadas de 1940 e 1950.

A orientação do Ministério das Cidades apesar de pressupor uma participação junto às esferas de mobilização local, tais como as associações de moradores, conselhos, fóruns, retira desses espaços as perspectivas 
de luta. A prerrogativa da participação popular identificada é como uma forma de legitimação das etapas do trabalho social. As mobilizações engajadas politicamente ficam a rebote das ações particulares de grupos profissionais vinculados aos projetos profissionais mais progressistas e emancipatórios. Ainda que se assuma este perfil, o padrão de avaliação adotado para o trabalho social não permite qualificá-las. É incabível nos moldes adotados para o trabalho social, posto que se trata de mudanças moleculares que se operam em determinado espaço e tempo, não sendo registrável em números tão somente, como é proposto. Desta forma, estas iniciativas estão fora do cálculo de medição do trabalho social, deixando evidente, que se trata somente de uma participação traduzida em números de participantes em assembleias, reuniões e etc. (PIMENTEL, 2012, p. 7).

Esta noção de participação social salientada por Pimentel (2012) é bem explorada nos manuais do TS, que solicitam uma quantificação do atendimento das demandas sociais apresentadas pelos mesmos e entendem como participação social a presença física dos moradores nas atividades desenvolvidas pelo trabalho conjunto.

A exemplo dos conceitos de participação tratados por Santana (2013), no processo de gestão democrática das cidades devem ser considerados como marcos a discussão do Estatuto das Cidades (2001) e o movimento da reforma urbana. Nesses momentos, foram debatidos alguns instrumentos de participação, como: 1) participação por meio de democracia direta, baseada nos ideais de cidadania e justiça social, a partir do controle social dos gastos públicos; 2) noção de participação vinculada à democracia representativa, via disputa por dentro do Estado e com base no exercício da política, que propiciou experiências interessantes, como as do orçamento participativo nas prefeituras do sul do país, no processo de democratização brasileira; 3) participação social, apresentada nos projetos habitacionais por meio do planejamento territorial desses projetos de intervenção durante a execução das obras e, posteriormente, nos projetos de geração de trabalho e renda, mobilização comunitária, formação das redes de território, organizadas pela sociedade civil e identificação de redes já existentes nas comunidades nos projetos de habitação atuais.

No trabalho social desenvolvido no PMCMV é abordada a terceira noção de participação social sob uma nova perspectiva. Nesta, deve-se incluir a população nas decisões do projeto e nas atividades de pós-ocupação dos moradores à nova realidade habitacional, tanto nas ações executadas por produção habitacional, quanto nos projetos de urbanização e regularização fundiária, quando são mobilizados os moradores residentes em assentamentos precários, favelas e loteamentos populares.

Essa participação na fase inicial do projeto arquitetônico ocorre com maior frequência quando se trata da demanda fechada, ou seja, proveniente de um mesmo assentamento ou de grupo de moradores de um bairro remanejado para condomínios habitacionais. Considera-se que a parti- 


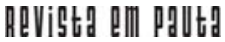

\} EXPERIÊNCIAS PIONEIRAS DE PARTICIPAÇÃO POPULAR - OLIVEIRA, N. C. \}

DOI: $10.12957 /$ REP.2017.32740

cipação iniciada no processo de discussão do projeto físico pode criar mais vínculos entre os moradores e o novo local de moradia, desenvolvendo também maior sensação de pertencimento e contribuindo para criação de identidade ao território.

Contudo, quando se refere à demanda aberta, ou seja, por sorteio, como na maioria dos casos, isso não ocorre. Dessa forma, a participação é incentivada para "referendar" o projeto físico, modelo adotado do PMCMV em todo o Brasil, sem discussão das demandas específicas dos moradores. Portanto, deve ser considerado que tais propostas podem acrescentar e modificar o projeto físico de modo a atendê-los com maior satisfação. Por consequência, é notável que haja uma falta de temporalidade entre o projeto físico e o projeto social com os moradores do PMCMV, acarretando alterações no modo de vida dos moradores dos condomínios habitacionais.

\section{Conclusão}

Como podemos observar com este apanhado histórico, este processo de inserção do Serviço Social no movimento popular nos possibilita algumas conclusões. O trabalho social desenvolvido pelos assistentes sociais, entre as décadas de 1950 e 1960, tinha a mobilização comunitária e a participação social como pressupostos das estratégias profissionais, com objetivo de aproximação direta com a classe trabalhadora. Por meio das experiências vividas pelos assistentes sociais de assessoria aos movimentos sociais urbanos, com os projetos de extensão e estágio em comunidades e bairros populares, pautados no trabalho de educação popular e organização comunitária, nas décadas de 1970 e 1980, aprofundamos nossa relação com a população no que se refere às lutas urbanas e à ampliação da cidadania. Atualmente, observamos que o trabalho social nos condomínios do PMCMV e moradias populares possui um caráter de controle social da força de trabalho, devido às normativas, manuais e orientações ditadas pela Caixa Econômica Federal, órgão fiscalizador do programa habitacional.

Apesar do caráter repressivo e cerceador de atividades políticas, durante a Ditadura Militar o trabalho social teve grande importância para organização popular dos moradores de favelas, comunidades, bairros populares e periferias. Essa relevância não era somente no sentido de subsidiar informações, contribuindo para ações reivindicatórias pelo direito à cidade, mas também para adaptação à nova moradia, nos processos de remanejamento de famílias para condomínios habitacionais. Além disso, deu suporte e apoio na formação de associações de moradores e grupos de interesse, papel este que se assemelha ao trabalho social desenvolvido nos condomínios do PMCMV. As novas requisições socioinstitucionais ao trabalho do assistente social, neste campo, colocam novos desafios, tais quais, a construção de novas redes sociais no território para atendimento 


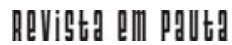

\} EXPERIÊNCIAS PIONEIRAS DE PARTICIPAÇÃO POPULAR - OLIVEIRA, N. C. \}

DOI: $10.12957 /$ REP.2017.32740

das famílias, como se a articulação destas redes representasse ações intersetoriais e pudesse reverter o processo de segregação socioespacial das moradias.

Ainda sobre o trabalho social desenvolvido nos condomínios do PMCMV, o Ministério das Cidades, com o excesso de normatização e mudanças na legislação sobre o trabalho social, vem apresentando estratégias de padronização e codificação da prática profissional que permitam à CEF "medir" o trabalho social para, então, aprová-lo ou não, pagá-lo ou não. Isto repercute na restrição da autonomia e criatividade nas metodologias e propostas de trabalho das equipes sociais das prefeituras e empresas. Estas se tornam limitadas, enfatizando processos de trabalho mais burocráticos e tecnificados, diferentemente do que fora experimentado em outros momentos da nossa trajetória histórica neste campo. Contudo, inscrevemos esta contradição como um processo político, no qual o assistente social é sujeito da história e a transformação dessa condição perpassa um processo organizativo da categoria profissional. 


\section{ReVistg all p. p.tg}

\} EXPERIÊNCIAS PIONEIRAS DE PARTICIPAÇÃO POPULAR - OLIVEIRA, N. C. \}

DOI: $10.12957 /$ REP.2017.32740

\section{Referências}

AMAMANN, S. B. Ideologia do desenvolvimento de comunidade no Brasil. São Paulo: Cortez, 1980.

. Ideologia do desenvolvimento de comunidade no Brasil. São Paulo: Editora Cortez, 2013.

ARAÚJO, M. J. S., et al. Profissional-População uma luta conjunta. Revista Serviço Social e Sociedade, ano III, n. 5, mar. 1982.

BRASIL. MINISTÉRIO DAS CIDADES. Capacitação na modalidade ensino a distância - trabalho social em programas de habitação de interesse social. 2014a. Disponível em: <http://cidades.nute.ufsc.br/downloads/MCidades _bookweb.pdf >. Acesso em: 20 fev. 2016.

. Portaria $n^{\circ}$ 21/2014. Aprova o Manual de Instruções de Trabalho Social nos Programas e Ações do Ministério das Cidades. 22 de jan. 2014b. Disponível em: <http://www.cidades.gov.br/images/stories/ArquivosCidades/ PAC/Manuais-Gerais-PAC/portaria21.pdf >. Acesso em: 20 fev. 2016.

. CAIXA ECONÔMICA FEDERAL. Manual temático: fortalecimento das organizações da sociedade civil. Oficina da Caixa Econômica Federal, vol. 2, 2014b. Disponível em: <www.avsi-usa.org/docs/pdf/Brazil-IntegUrban-Manual1-Plan-pt.pdf>. Acesso em: 20 fev. 2016.

CARDOSO, I. Processo de trabalho do Serviço Social. In: ABEPSS/CEDEPSS. Proposta básica para o projeto de formação profissional. Novos subsídios para o debate. Cadernos ABEPSS, n. 7, 1997.

GOMES, M. F. C., LEGRINO, A. I. C., FERNANDES, L. L., REGINENSI, C. Desigualdade e Exclusão nas Metrópoles Brasileiras. Editora Arco-Íris. Rio de Janeiro, 2006.

IAMAMOTO, M. O Serviço Social em tempo de capital e fetiche. São Paulo: Cortez, 2008.

LEFEBVRE, H. O direito à cidade. São Paulo: Moraes, 2001.

LIMA, S. A. B. Participação social no cotidiano. São Paulo: Cortez e Moraes, 1979.

PAZ, R.; TABOADA, K. J. Curso a distância, trabalho social em programas e projetos de habitação de interesse social. Brasília: Ministério das Cidades, set. 2010.

PAZ, R. S. O. C., et al. O Serviço Social e os movimentos sociais - uma experiência de trabalho em loteamentos clandestinos. Revista Serviço Social e Sociedade, ano II, n. 5, mar. 1981.

PIMENTEL, J. R. O trabalho social no contexto da atual política nacional de habitação: a difusão de um modelo e as implicações para o exercício profis- 


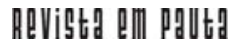

| EXPERIÊNCIAS PIONEIRAS DE PARTICIPAÇÃO POPULAR - OLIVEIRA, N. C.

DOI: $10.12957 /$ REP.2017.32740

sional do assistente social. Revista Convergência Crítica "Movimentos Sociais, Direitos e Sociedade, v. 1, n. 1, 2012.

SANTANA, J. Gestão das cidades no Brasil: estratégias e orientações do Banco Interamericano de Desenvolvimento. Campinas: São Paulo, 2013.

SILVA, M. L. L. S. Serviço Social de Comunidade: numa visão de práxis. $2^{a}$ edição. São Paulo. Editora Cortez, 1983.

SIQUEIRA, F. C. A. et al. As contradições e o espaço profissional na prática do assistente social. Revista Serviço Social e Sociedade, ano III, n. 8, mar. 1982.

DOI: 10.12957/rep.2017.32740

Recebido em 29 de agosto de 2017.

Aprovado para publicação em 30 de novembro de 2017.

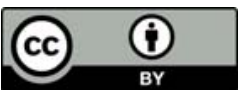

A Revista Em Pauta: Teoria Social e Realidade Contemporânea está licenciada com uma Licença Creative Commons Atribuição 4.0 Internacional. 